\title{
Study on Promotion Effect on School Sports Culture Construction by Shaanxi Traditional Ethnic Sports
}

\author{
$\mathrm{Li} \mathrm{Li}$ \\ Shaanxi Xueqian Normal University \\ Xian, China
}

\begin{abstract}
Traditional ethnic sports is an important part of Chinese traditional culture, and it has developed and been carried forward very well with its uniqueness, regional characteristics and inheritance in the development of China's long history. School sports culture is one of the culture types generated in a fixed environment of campus, and one of the important forms to reflect the school's comprehensive strength. Taking Shaanxi province as the regional background, this paper mainly analyzes and researches to the correlation between its traditional ethnic sports and school sports culture construction, so as to constantly promote the substantial development of sports culture.
\end{abstract}

Keywords-Shaanxi province; traditional ethnic sports; school sports culture; construction

\section{INTRODUCTION}

The traditional ethnic sports culture of Shaanxi province is of certain regional characteristics and diversity compared to Chinese traditional ethnic sports culture as a whole. Its sports culture has distinct characteristics, and traditional ethnic sports mainly combine sports practice and national spirit together in the development process, to reflect the Chinese cultural connotation. The integration and application of traditional ethnic sports in college sports education are beneficial to their mutual complementation and development, and which will help to increase students' cohesion and national confidence, thus to realize the spread of sports culture and national culture. Therefore, it remains one the important issues for the modern education circle and sport circle to study the correlation between traditional ethnic sports and school sports culture construction studied with emphasis.

\section{RESEARCH BACKGROUND OF SHAANXI TRADITIONAL ETHNIC SPORTS AND SCHOOL SPORTS CULTURE} CONSTRUCTION

Shaanxi province has a long history and is one of the important birthplaces of Chinese national culture with a lot of cultural heritage. In the development history, Shaanxi native culture and regional culture have developed and improved continuously on the basis of national culture development, thus today's various historical and cultural resources and traditional ethnic sports resources are formed. Shaanxi traditional ethnic sports culture has gradually formed the spots culture with northern Shaanxi, Guanzhong and southern Shaanxi as regional background based on many of the local factors such as economy, culture, climate and history [1], possessing unique regional culture characteristics. Therefore, it is an inevitable development trend of Shaanxi sports and culture and other related contents to research the correlation between traditional ethnic sports and school sports culture in Shaanxi province, which will be beneficial to the development of traditional ethnic sports resources and the effective construction of school sports culture in Shanxi province, and is advantageous to the reform of physical education and the transformation of students' sports concept.

Therefore, on the basis of the abovementioned and taking a large number of data and literature related to traditional sports as the research background, this paper has conducted a basic research on school sports culture construction and traditional ethnic sports in Shaanxi province, so as to provide the objective and real theory basis for the construction and research of school sports culture.

III. ANALYSIS OF SHAANXI TRADITIONAL ETHNIC SPORTS' FUNCTION AND IMPORTANCE IN PROMOTING SCHOOL SPORTS CULTURE CONSTRUCTION

\section{A. It is Advantageous to the Students to Form A Good Thinking and Moral Conception}

Modern education teaching, the teaching of Moral education has always been the core of school teaching in different stages in modern education. Campus sports culture is formed in the long-term construction and development of school, therefore, it is of a certain function of moral education, affecting the formation of students' good ideological and moral concepts and quality. Traditional ethnic sports contains the outstanding traditional culture of our country, including such concepts of national development as hard work, perseverance and justice, which is advantageous to the formation of students' collective spirit and team consciousness [2]. Sport activities belong to the competitive activities, so most sports require a lot of people to participate in. Relevant team spirits may be reflected while students participate in sports and activities, influencing their thinking construction and good quality formation subtly.

The culture of Shaanxi province has a long history, and school sports culture construction is closely related to Shaanxi traditional ethnic sports culture. If the sport items of Shaanxi traditional ethnic sports such as martial arts, rope skipping, and waist drum and Yangge will be reflected in school sports 
culture construction, then the thinking and quality of traditional sports culture with positive meaning will gradually penetrate into the school sports culture. Students may feeling the culture with long history through participating in traditional sports activities, continuously promote the formation of their own correct values, and promote the construction of their own good moral consciousness, thus to realize perfect development of themselves.

\section{B. It is Advantageous to the Construction and Cultivation of Students' Mind}

The effect of Shaanxi traditional ethnic sports resources on the construction and formation of students' good mind in campus sports culture construction mainly reflects in the following aspects: first, the effective development of traditional ethnic sports and sport activities are beneficial to the growth of students' thinking nerve, providing a certain biological basis for the development of students' learning and intelligence at the later period; Second, while participating in sport activities, students' hearing and balance as well as other organs and functions will be mobilized uniformly, all kinds of information will be input into the students' cerebral cortex center [3], which can be beneficial to the improvement of oxygen supply to brain cells, and promote the development of students' quick-thinking and mental maturity; third, campus sports activity is of certain openness, students will gradually achieve the development of creative activities while participating in sports to improve self ability, thus to improve the students' thinking development, promote the improvement and construction of students' creativity and imagination.

Shaanxi traditional ethnic sports contains a variety of sport items with different developmental functions, for example, intelligence items mainly include Paomacheng, Liuzichong and Diufang and so on, while in terms of physical function exercise, it contains such martial arts as Paochui, Goulianqiang, Chunqiudadao, Fanziquan and Tongbeiquan and so on which are of the characteristic of Shaanxi province. Martial arts are activity items generally carried out in various regions of Shaanxi province. People constantly develop and perfect the martial arts on the basis of existing martial arts, thus the various martial arts with physical exercise function are formed. Therefore, the integration of Shaanxi traditional ethnic sports culture and school sports culture is of important significance for the overall development of students' mind and physical functions.

\section{It is Beneficial to Students' Aesthetic Education}

Campus sports culture activities are of the particularity of their own functions, therefore, they are of great significance for improvement of students' comprehension and appreciation ability toward beautiful things. In general, the effect of campus sports culture activities on the students' aesthetic education development mainly reflects in the cultivation of healthy body as well as the knowledge and skills about beauty. While carrying out campus sports activities, physical education teachers can use the artistic action and language to improve the traditional sports teaching, enable students to master sports skills on the basis of that [4] to achieve aesthetic education, so as to realize the sound development of their own thinking awareness.

The application of Shaanxi traditional ethnic sports in school sports culture can effectively promote the improvement of school sports functions. For instance, introduce the waist drum, Yangge, stilt walk and other forms of sport activities with local characteristics, and conduct the arrangement, organization and training of them, making the students fully perceive the traditional cultures contained in traditional sports while carrying out the sport activities, to realize cultural heritage and good teaching of sports.

\section{CURRENT DEVELOPMENT SitUATION OF TrAditionAL ETHNIC SPORTS IN SCHOOLS IN SHANXI PROVINCE}

\section{A. Traditional Ethnic Sports Curriculum is Carried out Lack of Integrity}

In general, traditional ethnic sports in China mainly include the martial arts, folk sports and traditional health sport. Currently, as for the current development situation of ethnic sport teaching in various schools in Shaanxi province, martial arts are the main items, while the other two items accounting for less proportion compared with martial arts. Among which, the sport activities with national characteristics of Shaanxi province and strong interactivity and interestingness such as waist drum, Yangge and stilt walk are failed to be taught in sports classroom. In addition, the traditional ethnic sport items with the function of preserving one's health and fitness are also failed to be reflected in the sports teaching course at present stage of Shaanxi province [5]. The teaching contents and methods of martial arts sport items in most of the schools are traditional and backward, which is difficult to promote effective development of the traditional ethnic sports such as martial arts.

\section{B. Lack of Attention to Traditional Ethnic Sports Teaching from School Leaders}

It can be found in the actual investigation and study that most of the school leaders are not familiar with traditional ethnic sports, lack of integrity cognition of related contents. And there are no professional teachers to conduct relevant teaching and management of the activities related to Shaanxi traditional ethnic sports. Government departments are lack of certain cognition in traditional ethnic sports teaching, and lack of support to related policy and capital projects, which have resulted in the lack of integrity teaching and effective development of traditional ethnic sports in the schools in Shanxi province.

In addition, various schools in each region of Shaanxi only pay attention to the courses of martial arts in traditional ethnic sports teaching, and lack of attention to the representative activities of various regions. At present, along with our country's protection of and attention to local intangible cultural heritage, part of the sports culture and sport items have inherited and protected to a certain degree, but the protection power is limited. So various schools need to conduct the teaching and talent cultivation in terms of traditional ethnic courses in sports teaching, to make more 
students inherit and research Shaanxi traditional ethnic sports culture and related theories, so as to continuously promote the sound development of Shaanxi folk sports resources and culture and its construction.

\section{RESEARCH ON THE FUNCTION MEASURES OF SHAANXI} Traditional ETHNIC SPORTS IN PROMOTING SCHOOL SPORTS Culture Construction

\section{A. Inherit the Traditional Ethnic Sports Scenically}

Traditional ethnic sports are the cultural accumulation in the long-term development of our country and an important part of traditional Chinese culture, having a very high social history and application value. In the development of modern society, traditional sports have some characteristics such as entertainment and appreciation. But with the continuous development of traditional ethnic sports, although the traditional ethnic sports have many excellent forms and are of important resource application value, the inadaptability of traditional Chinese sports to the society general appear with the development of modern society. Therefore, in the inheritance and application of Shaanxi traditional sports [6], we shall constantly perfect the connotation of traditional ethnic sports according to the era's development demand, take the good and discard the bad ones, to realize the innovation of cultural integration, cultural form and cultural contents by referring to foreign sports culture in combination with the actual development situation, to constantly promote the development of traditional ethnic sports, and to promote its function of application and development of school sports culture construction.

\section{B. Organize the Traditional Ethnic Sports Cultural Festival in School}

The ethnic sports cultural festival is one of the important forms to carry forward traditional ethnic sports for the school, the development of this form may help to effectively realize the inheritance and succession of national culture, enrich the contents and forms of college sports culture, promote student's perception of traditional sports culture, and increase their interests in physical education learning, thus to promote the development of sports.

In developing the sports cultural festival, various schools in Shanxi province shall pay attention to the cultivation of their own sports cultural values, and express contemporary students' love toward traditional national culture as well as the history and culture of traditional culture itself to meet different needs of the students, so as to realize the development and spreading of traditional ethnic sports culture. Shaanxi traditional ethnic sports cultural festival contains the different ethnic sport items in different parts of Shaanxi. Therefore, the development of such type of sports is good for students' learning of traditional ethnic sport activities [7], to constantly promote national communication between various regions of Shaanxi province, to promote the construction of traditional ethnic sports culture in various schools, and to constantly realize modern sports construction requirements and construction goals.

\section{Strengthen the Construction of Traditional Ethnic Sports Talent Team}

As for the construction of traditional ethnic sports talent team, attention shall be paid to the cultivation of traditional sports theoretical knowledge and practical ability, thus the following methods can be adopted to achieve effective talent training.

First of all, various schools should strengthen the amplification of physical education subject scope, and add traditional ethnic sports course on the basis of the existing sports curriculum to the greatest extent.

Second, strengthen the enhancement of physical educators' comprehensive ability and comprehensive quality, train the teachers regularly, and hold all kinds of seminars related to traditional ethnic sports, enhance teachers' theory and technical ability. At the same time, intensify the researches on traditional ethnic sports contents in physical education, establish a complete evaluation system with strong applicability, constantly promote the innovation of traditional ethnic sports by physical educators, and intensify investment in physical education. If the condition allows, employ the teachers with higher qualification to teach, to realize integrated teaching of the course.

Finally, give full play to its important functions of construction and development by virtue of various sports organizations, and constantly organize students to participate in relevant sports, to enrich students' sports activity types, and to promote the development of traditional ethnic sports.

\section{Insist on Reform and Innovation of Traditional Ethnic Sports}

Innovation is the basis and the important form for the development of things, playing a very important role in the social development of our country, the development of Chinese sports undertakings, especially the traditional ethnic sports, is short of certain innovation ability. Therefore, Shaanxi province break the limitations of conditions and rules on the basis of its own traditional ethnic sports, to innovate unceasingly, and combine traditional ethnic sports with students' social practice forms organically, enhance innovation and reform in competition system, rules and methods, to constantly promote the development of Shaanxi traditional ethnic sports.

\section{CONCLUSION}

To sum up, thanks to the unique local culture and resource advantage of Shaanxi province, Shaanxi traditional ethnic sports resources are of certain particularity, and of very important significance in the development of traditional ethnic sports in China. Therefore, at present, Shaanxi province should pay attention to the research on the correlation between traditional ethnic sports and campus sports culture construction, to constantly use the advantages of traditional ethnic sports to realize physical education teaching reform in schools, promote the cultivation of the students' lifelong sports consciousness, and realize the sound development of sports culture in China. 


\section{REFERENCES}

[1] Gu Guoqiang. On the Affect on College Sports Culture by Traditional Ethnic Sports [D].Southwest University, 2010.

[2] Jiang Xia, Ma Yue. Construct College Campus Sports Culture based on Shaanxi Traditional Sports Resources [J]. Journal of Socialist Theory Guide,2010,03:99-101.

[3] Zhai Xiaoying. Research on Development Traditional Ethnic Sports Courses in Colleges in Shaanxi Province [D]. Hebei Normal University,2011.

[4] Zhang Wenjuan. Research on the School-oriented Construction of Resource Library of Shaanxi Traditional Ethnic Sport Items [D]. Xi'an Physical Education University, 2012.

[5] Li Aiqin. Research on Development Status of Traditional Ethnic Sports in Cultural Construction of New Countryside in Songshan Area of Henan Province and Countermeasures [D]. Beijing Sport University, 2012.

[6] Xin Xican. Study on SWOT Analysis and Strategies of Traditional Ethnic Sports Development under Ethnic Culture Ecological Village Mode [D]. Yunnan Normal University, 2014.

[7] Wu Lan. Study on the Development Situation, Inheritance and Development of Shaanxi Traditional Sports [D]. Shaanxi Normal University, 2011. 